\title{
Stability of Microwave and Electronic Devices: an Approach from Dynamical Systems Theory
}

\author{
UDK 621.37 .01
}

IFAC IA $5.8 .0 ; 4.1 .4$

Original scientific paper

\begin{abstract}
The general problem of stability of microwave and RF devices and circuits in the presence of multi-frequency or broadband signals is addressed. The problem is formulated in terms of the system of nonlinear non-autonomous differential equations for generalized coordinates in the phase space that can be attributed to, e.g., amplitudes of electric currents in circuits with lumped elements or mode amplitudes of the electromagnetic field in the distributed systems. An approach to the stability analysis is proposed that allows predicting the appearance of various kinds of instabilities including the deterministically chaotic motion. The new criterion based on the analysis of Lyapunov exponents is discussed that establishes the relation between maximal stable amplitude of oscillations and the levels of nonlinearity and damping in the system. The examples of one- and two-mode oscillators have been considered in detail.
\end{abstract}

Key words: chaos, Lyapunov exponents, microwave circuits, oscillators, instability

\section{INTRODUCTION}

The analysis of the structure of electromagnetic field in electronic devices or complex transformation of broadband signals in RF circuits can be reduced in many cases to the study of interaction between several coupled oscillators. Such classical problems of circuit theory as generation of oscillations, frequency conversion, parametric amplification, etc. can be efficiently formulated and solved in terms of temporal variation of amplitudes and phases of generalized modes. From the mathematical viewpoint, such a description requires solving a set of deterministic differential equations for the time evolution of the generalized coordinates controlled by the set of external and internal parameters (physical properties of the system). It should be noted, that the equations describing the dynamics of the system are typically nonlinear, therefore, the solutions cannot be expressed in elementary or special functions and some approximate or numerical methods have to be used.

The issue of stability plays a key role in the theory of nonlinear oscillations, due to its importance in applications in the development and utilization of concrete devices and systems. Until very recently, the stability analysis in nonlinear dynamical systems was based on the assumption that only periodic and quasiperiodic motion can exist in the stationary regime. Under such an assumption, the final goal of predicting the stability of the given system at the given values of controls can be reached by the Floquet-type analysis $[1,2]$ of linearized equations in the vicinity of a stationary periodic or quasiperiodic oscillation. Nowadays, with the discovery of the phenomenon of deterministic chaos, it became clear that the traditional methods of stability analysis have to be revised with taking into account the possibility for the chaotic motion to appear. On the other hand, the burst of activity in the field of nonlinear dynamics spurred by this discovery in the middle of 60 -s, has led to the invention of new powerful methods of analysis that can be efficiently applied for predicting the raise of instabilities in dynamical systems of virtually any physical origin, including various electronic devices and circuits [3].

In this paper we apply a recently proposed method of stability analysis [4] based on the notion of Lyapunov exponents for predicting the general kind of instability in oscillatory systems. From a slightly different perspective, the method establishes the threshold of stability in terms of the amplitude of oscillations that guarantees the stable operation of the devices or circuits described by similar sets of differential equations. Lyapunov characteristic exponents (LCE) provide a quantitative measure of stretching and contracting deformations of an infinitesimally small phase space sphere in the vicinity of an arbitrary trajectory in a dynamical system. So defined, they also characterize the divergence (convergence) rates of two initially close trajectories residing on an attractor and serve as indicators of the stability of motion. Total number of Lyapunov exponents that a system possesses is equal to the dimension of the phase space, or, in other words, the number of independent variables necessary to fully characterize the 
motion. Being invariant under a smooth change of coordinates, LCE provide a useful quantitative measure of stability for various types of motion including complex quasiperiodic orbits and chaos and, together with other dynamic invariants like fractal dimension and Kolmogorov-Sinai entropy play an important role in the theory of nonlinear dynamical systems.

\section{PROBLEM STATEMENT: MATHEMATICAL FORMALISM}

Under rather general assumptions on the type of dynamical system that models, e.g., the electric current in a simple nonlinear circuit [1] or the temporal variation of mode amplitude in a electromagnetic resonator filled with a nonlinear medium [3], the mathematical description can be given by differential equations of the form

$$
\frac{\mathrm{d}^{2} x_{i}}{\mathrm{~d} t^{2}}+\omega_{0 i}^{2} x_{i}+\delta_{i} \frac{\mathrm{d} x_{i}}{\mathrm{~d} t}+N_{i}\left(\mathbf{x}, \frac{\mathrm{d} \mathbf{x}}{\mathrm{d} t}\right)=f_{i}(t)
$$

where $x_{i}$ is the generalized coordinate of $i$-th oscillator, $i=1,2, \ldots, m$, number of oscillators, $\omega_{0 i}-$ their natural frequencies, $\sigma_{i}$, damping parameters, $N_{i}($.$) , are nonlinear functions describing coupling$ between the oscillators and nonlinear properties of the system, $f_{i}(t)$, external perturbations. In the discussion given below, we restrict the consideration by the case of the focus type singular point at the origin of each oscillator that corresponds to the physically important case of small dissipation and coupling between oscillators.

It is evident that the set of nonlinear oscillators (1) belongs to a more general class of dynamical systems described by the equation

$$
\frac{\mathrm{d} \mathbf{x}}{\mathrm{d} t}=\mathbf{F}(\mathbf{x}, t), \quad \mathbf{x} \in \mathfrak{R}^{n} .
$$

To analyze the stability of an arbitrary solution of Equation (1) $\mathbf{x}^{*}(t)$, one has to consider the linearized system $[1,2]$

$$
\frac{\mathrm{d} \mathbf{y}}{\mathrm{d} t}=\hat{\mathbf{J}}\left(\mathbf{x}^{*}(t)\right) \mathbf{y},
$$

where

$$
\hat{\mathbf{J}}\left(\mathbf{x}^{*}(t)\right) \equiv \frac{\partial \mathbf{F}\left(\mathbf{x}^{*}(t)\right)}{\partial \mathbf{x}}
$$

is $n \times n$ time dependent Jacobian matrix, $\mathbf{y}$ is an $n$-vector in the tangent space corresponding to an infinitesimal perturbation of the trajectory $\mathbf{x}^{*}(t)$. The standard algorithm of calculating the spectrum of LCE [5] consists in solving the equations (3) simultaneously with (2) for a set of mutually orthonormal vectors $\left\{\mathbf{y}_{k}\right\}(k=1,2, \ldots, n)$ and estimating the average expansion rates for the lengths $\rho_{k}=$ $=\left\|\mathbf{y}_{k}\right\|$ of the vectors $\left\{y_{k}\right\}$. The general solution of the equation (3) is given by

$$
\mathbf{y}(t)=\hat{\mathbf{M}}(t) \mathbf{y}(0),
$$

where $\hat{\mathbf{M}}(t)$ is the fundamental matrix of solutions for the equation (3). It has been shown by Oseledec [6] that for almost any choice of initial conditions there exists the following long time limit for the initially orthonormal vectors $\mathbf{y}_{k}(0)$

$$
\lambda_{k}=\lim _{t \rightarrow \infty} \frac{1}{t} \ln \left\|\hat{\mathbf{M}}(t) \mathbf{y}_{k}(0)\right\| .
$$

In other words this means that asymptotically, in the limit of $t \rightarrow \infty$, the evolution of $\left\|y_{k}\right\|$ is approximated by $\left\|\mathbf{y}_{k}(t)\right\|=\left\|\mathbf{y}_{k}(0)\right\| e^{\lambda_{k} t}$, where the exponents $\lambda_{k}$ constitute the spectrum of LCE.

The equation (3) can be rewritten in the polar coordinate frame for the amplitude $\rho=\|\mathbf{y}\|$ and directions $\varphi_{m}(m=1,2, \ldots, n-1)$ of an arbitrary vector $\mathbf{y}$ in the tangent space.

$$
\begin{gathered}
\frac{\mathrm{d}}{\mathrm{d} t}[\ln \rho(t)]=P\left(\varphi_{1}, \varphi_{2}, \ldots \varphi_{n-1}\right), \\
\frac{\mathrm{d} \varphi_{m}}{\mathrm{~d} t}=\Phi\left(\varphi_{1}, \varphi_{2}, \ldots \varphi_{n-1}\right),
\end{gathered}
$$

where $y_{l}$ are Cartesian components of the vector $\mathbf{y}, \rho^{2}=\sum_{l=1}^{n} y_{l}^{2}$; and the angles $\varphi_{m}$ can be found by the direct formulas defining the transition from Cartesian to spherical coordinates in $\mathfrak{R}^{\prime \prime}$ [4].

It is easy to show merely from the definition of the LCE that

$$
\lambda_{k}=\lim _{T \rightarrow \infty} \frac{1}{T} \int_{0}^{T} P_{k}\left(\varphi_{1}(t), \ldots \varphi_{2}(t), \ldots, \varphi_{n-1}(t)\right) \mathrm{d} t .
$$

i.e., the LCE are long time averages of corresponding functions of angular coordinates of the vectors $\left\{\mathbf{y}_{k}\right\}$. The functions $P_{k}\left(\varphi_{1}(t), \varphi_{2}(t), \ldots, \varphi_{\mathrm{n}-1}(t)\right)$ depend on both the time and phase space coordinates and constitute the spectrum of instantaneous growth rates $\mu_{k}(t)$.

$$
\mu_{k}(t)=\frac{\mathrm{d}\left[\ln \rho_{k}(t)\right]}{\mathrm{d} t}=P_{k}\left(\varphi_{1}(t), \varphi_{2}(t), \ldots, \varphi_{n-1}(t)\right) .
$$

If we arrange the values of $\lambda_{k}$ in descending order, then the instability means the positive value of the first (largest) LCE, i.e. $\lambda_{1}>0$. It is evident, that $\lambda_{1}$ can take a positive value only if $\mu_{1}$ can be greater than zero. On the contrary, if the inequality

$$
\mu_{1}(t)<0
$$


holds all the time, the system is asymptotically stable, i.e. all the perturbations are exponentially shrinking with time and, hence, unstable motions are precluded. From the inequality (6), together with Equations (2), (3), it appears possible to obtain the relation between the control parameters and phase space coordinates which guarantees that the system is "safe « in the sense that, if the trajectory never leaves the region with negative values of $\mu_{1}$, no instability appears. The goal is reached by analyzing the structure of the function $P_{1}\left(\varphi_{1}(t), \varphi_{2}(t), \ldots, \varphi_{n-1}(t)\right)$, together with solutions of Equation (2), which define the dynamics of angles $\varphi_{m}$ through Equations (5). It should be however noted that a straightforward calculation of the function $P_{1}$ does not always lead to the explicit equation for the border of the asymptotic stability area in the phase space. This happens due to the presence of both the expanding and contracting directions around a typical trajectory that is a consequence of the affine character of the phase flow in the vicinity of a generic stable fixed point. Fortunately, the particular form of the function $P_{1}$ depends on the choice of coordinates, and in many cases it turns out possible to obtain the borders of the asymptotic stability area by introducing a linear change of coordinates diagonalizing the linear part of the flow $\mathbf{F}(\mathbf{x}, t)$ in the vicinity of an arbitrary point in the phase space. This kind of transformation is known to be a standard tool in the analysis of differential equations [7].

\section{NON AUTONOMOUS PASSIVE NONLINEAR OSCILLATOR}

As an example of a particular system governed by the equations of the type (1), we take the single nonlinear oscillator (motion in a potential well with a potential $U(x)$ defined by $\left.N(x) \equiv \frac{\mathrm{d} U(x)}{\mathrm{d} x}\right)$

$$
\frac{\mathrm{d}^{2} x}{\mathrm{~d} t^{2}}+\delta \frac{\mathrm{d} x}{\mathrm{~d} t}+\omega_{0}^{2} x+\varepsilon N(x)=f(t)
$$

that has been used as a basic model in many problems of mechanics, electronics, optics, electromagnetic field theory, etc.

By introducing the variables $x_{1}=x^{\prime}, x_{2}=\mathrm{d} x / \mathrm{d} t$ the system (7) is transformed to the standard form

$$
\begin{aligned}
& \frac{\mathrm{d} x_{1}}{\mathrm{~d} t}=x_{2} \\
& \frac{\mathrm{d} x_{2}}{\mathrm{~d} t}=-\delta x_{2}-\omega_{0}^{2} x_{1}-\varepsilon N\left(x_{1}\right)+f(t)
\end{aligned}
$$

and the variational equations (3) in the vicinity of an arbitrary trajectory $x^{*}(t)$ for this system look like

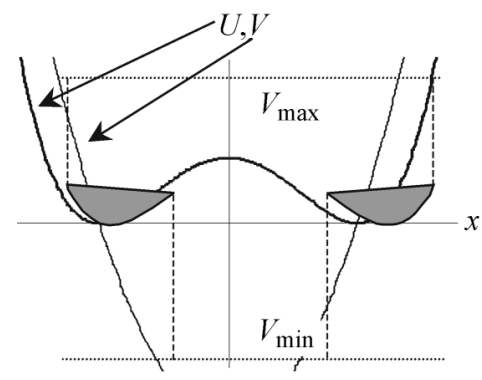

Fig. 1 Areas of asymptotic stability (shaded) for the case of cubic potential (Duffing oscillator)

$$
\begin{aligned}
& \frac{\mathrm{d} y_{1}}{\mathrm{~d} t}=y_{2} \\
& \frac{\mathrm{d} y_{2}}{\mathrm{~d} t}=-\omega_{0}^{2} y_{1}-\delta y_{2}-\varepsilon V\left(\left(x^{*}(t)\right) y_{1}\right.
\end{aligned}
$$

where $y_{1,2}$ are the components of the perturbation vector $\mathbf{y}$,

$$
V\left(x^{*}(t)\right)=\left.\frac{\mathrm{d} N}{\mathrm{~d} x_{1}}\right|_{x_{1}=x^{*}(t)} .
$$

Then, after the coordinate transform recasting the linear part of Equation (8) to the canonical (diagonal) form, the explicit expression for the growth rate $\mu_{1}$ follows directly from its definition and the equation for the norm of $\|\mathbf{y}\|=\rho$ in the polar coordinates:

$$
\mu_{1}(t)=\frac{1}{2}\left[-\delta-\frac{2 \varepsilon}{\sqrt{4 \omega_{0}^{2}-\delta^{2}}} V\left(x^{*}(t)\right) \cos (2 \varphi)\right],
$$

Under the assumption that $\varphi$ can take any value in the interval $[0 ; 2 \pi]$ we obtain the explicit formulas for the border of the asymptotic stability area

where

$$
V_{1}<\varepsilon V(x)<V_{2}
$$

$$
V_{1,2}=\mp \frac{1}{2} \delta \sqrt{4 \omega_{0}^{2}-\delta^{2}}
$$

Inequalities (10) thus define the limits of variation for the function $V(x)$ and, hence, for the coordinate $x$ of the nonlinear oscillator (7), ensuring the asymptotic stability of motion.

\section{TWO COUPLED OSCILLATORS}

Two nonlinear oscillators with a diffusive coupling is a classical system in the circuits theory. It constitutes a natural generalization of a single-degree-of-freedom nonlinear oscillator to a more complex dynamical system, necessary for understanding the multi-mode interactions in the spatially distributed devices, like, e.g., optical wave-guides or electronic tubes. In the simplest case of identi- 
cal oscillators with cubic nonlinearity $\left(N(x)=\beta x^{3}\right)$ and linear coupling, the system is described by the following equations

$$
\begin{aligned}
& \frac{\mathrm{d}^{2} x_{1}}{\mathrm{~d} t^{2}}+\omega_{0}^{2} x_{1}+\beta x_{1}^{3}+\delta \frac{\mathrm{d} x_{1}}{\mathrm{~d} t}+\kappa x_{2}=f_{1}(t) \\
& \frac{\mathrm{d}^{2} x_{2}}{\mathrm{~d} t^{2}}+\omega_{0}^{2} x_{2}+\beta x_{2}^{3}+\delta \frac{\mathrm{d} x_{2}}{\mathrm{~d} t}+\kappa x_{1}=f_{2}(t)
\end{aligned}
$$

where $\kappa$ stands for the coefficient of coupling between the oscillators. The direct application of the approach given above combined with the canonical linear coordinate transform results in the following equation for the largest local expansion rate:

$$
\begin{gathered}
2 \mu_{1}(t)=-\delta-\frac{3 \beta}{2}\left[U\left(\frac{1}{\omega_{1}} \sin 2 \phi \cos ^{2} \theta+\frac{1}{\omega_{2}} \sin 2 \varphi \sin ^{2} \theta\right)+\right. \\
\left.+V\left(\frac{1}{\omega_{1}} \sin \phi \cos \varphi \sin 2 \theta+\frac{1}{\omega_{2}} \cos \phi \sin \varphi \sin 2 \theta\right)\right]
\end{gathered}
$$

where $U=x_{1}^{2}+x_{2}^{2} ; V=x_{1}^{2}-x_{2}^{2} ; \omega_{1,2}^{2}=\omega_{0}^{2}-\frac{\delta^{2}}{4} \mp \kappa$, $\phi, \varphi, \theta$ are the angles in Equation (5). Then, the condition of absolute stability (6) can be formulated for this system as

$$
x_{1}^{2}, x_{2}^{2}<\frac{\delta \omega_{1} \omega_{2}}{3 \beta\left(\omega_{1}+\omega_{2}\right)} \text {. }
$$

Therefore, the stability of the system of two coupled oscillators as a whole is defined by the amplitude of oscillations of each of its subsystems.

\section{CONCLUSION}

It has been recently recognized that in many oscillatory systems the threshold of instability may strongly depend on the frequency content of the external signal. As it was shown, e.g., in [8], the change of harmonic to bifrequency excitation in an equation of class (7) results in considerable lowering of the instability onset in the intensity of the external force. A natural question stems from these findings: what is the lowest possible level of excitation that can result in a destabilization of the system? As we have demonstrated with several examples of nonlinear oscillators, the analysis of asymptotic stability in terms of LCE allows answering this question and estimating the maximal stable amplitude of motion, and thus provides a necessary condition for any bifurcation to occur. We would like to stress that the method we propose is independent from the type of external force and dimensionality of the dynamical system, therefore, it yields a fundamental limit for all types of instabilities, including chaotic motion, to appear in a broad class of nonlinear circuits and systems.

\section{REFERENCES}

[1] C. Hayashi, Nonlinear Oscillations in Physical Systems. McGraw-Hill, New York, 1964.

[2] G. Floquet, Sur les Equations Differentielles Lineaires a Coefficients Periodiques. Ann. Ecole Norm. Super., vol. 2-12, pp. 47-88, 1883.

[3] V. B. Ryabov, D. M. Vavriv, Chaotic Instabilities in Singleand Multi-Mode Electronic Devices, in Low Temperature and General Plasmas. M. Miloslavljevic, Z. Petrovic (eds.), Nova Science, Belgrade, 1996.

[4] V. B. Ryabov, Using Lyapunov Exponents to Predict the Onset of Chaos in Nonlinear Oscillators. Phys. Rev. E, vol. 66, no. 1, pp. 016214-1-016214-17, 2002.

[5] J.-P. Eckmann, D. Ruelle, Ergodic Theory of Chaos and Strange Attractors. Rev. Mod. Phys., vol. 57, no. 3, pp. 617-656, 1985.

[6] V. I. Oseledec, A multiplicative Ergodic Theorem: Liapunov Characteristic Numbers for Dynamical Systems. Trans. Moscow Math. Soc. vol. 19, pp. 197-231, 1968.

[7] S. Wiggins, Introduction to Applied Nonlinear Dynamical Systems and Chaos. Springer, New York, 1990.

[8] A. D. Grishchenko, D. M. Vavriv, Dynamics of a Pendulum with a Quasiperiodic Perturbation. Tech. Phys., vol. 42, pp. 1115-1120, 1997.

Stabilnost mikrovalnih i elektroničkih aktivnih elemenata: Analiza primjenom teorije dinamičkih sustava. Razmotren je općeniti problem stabilnosti mikrovalnih i radiofrekvencijskih aktivnih elemenata i sklopova u prisutnosti višefrekvencijskih ili širokopojasnih signala. Problem je formuliran kao sustav nelinearnih neautonomnih diferencijalnih jednadžbi u poopćenim koordinatama faznog prostora koje se mogu pridružiti npr. amplitudama električnih struja u sklopovima od elemenata s koncentriranim parametrima ili amplitudama modova elektromagnetskog polja u sustavima s raspodijeljenim parametrima. Predložena je analiza stabilnosti koja omogućava predviđanje različitih vrsta nestabilnosti uključujući determinističko kaotično gibanje. Razmotren je novi kriterij koji se osniva na analizi Ljapunovljevih eksponenata. Taj kriterij uspostavlja vezu između najveće stabilne amplitude oscilacija te razina nelinearnosti i prigušenja u sustavu. Podrobno su analizirani primjeri jednomodnog i dvomodnog oscilatora.

Ključne riječi: kaos, Ljapunovljevi eksponenti, mikrovalni sklopovi, oscilatori, nestabilnost

\section{AUTHOR'S ADDRESS}

Vladimir B. Ryabov, Professor

Complex Systems Department Future University Hakodate

116-2 Kameda Nakano-cho, 041-8655 Hakodate city

Hokkaido, Japan

Phone: +81 - 0138-346129

Fax: +81 - 0138-34-6301

E-mail: riabov@fun.ac.jp

Received: 2004-10-23 